\title{
Impact of Poster Presentations on Academic Knowledge Transfer from the Oncologist Perspective in Turkey
}

\author{
Deniz Arslan ${ }^{1}$ Timur Koca ${ }^{2 *}$, Didem Tastekin ${ }^{3}$, Hamit Basaran$^{2}$, Hakan Bozcuk ${ }^{4}$
}

\begin{abstract}
Background: Currently poster presentations offer a common visual medium for knowledge transfer by a wide range of health professionals. Our study aimed to determine the scientific importance of poster presentations for Medical and Radiation Oncologists. Methods: A survey form including 40 questions was distributed to a total of 131 oncologists experienced in poster presentations. One hundred completed survey forms were included in the study. Descriptive statistics and modified thematic analyses were performed on the responses. Results: Overall $64 \%$ of the participants agreed that posters were a good medium for knowledge transfer. Some $88 \%$ agreed that concise and clear styled presentations would increase appealing interests for poster contents. Visual appearance was cited more influential than content of the subject; $70 \%$ of participants agreed that appearances of posters could help to draw more viewer attention. Of respondents, $63 \%$ believed that posters accompanied by their author were more attractive for congress attendees, and $33 \%$ of them declared that the halo effect of the poster presenter was also important. Conclusion: The present study indicated that intelligibility, appearance and visuality of posters are most important factors from the aspect of oncologist participants. Presenters must take into account these important points when preparing their academic posters.
\end{abstract}

Keywords: Poster presentation - academic knowledge transfer - oncologists - Turkey

Asian Pac J Cancer Prev, 15 (18), 7707-7711

\section{Introduction}

Similar to other fields in medicine, poster presentations in oncology is generally the first method of knowledge transfer for new research results (Rowe et al., 2009; Smith et al., 2004). Authors establish new horizons in their minds by the help of the debating environment by presenting their studies in various ways as a poster in scientific environments, which will enable them to benefit from knowledge of other participants as well as exchanging ideas and experiences with them.

Poster presentations in scientific meetings have started in 1970s in United States of America (USA) and then it has become the most commonly preferred presentation forms in knowledge transfer in congresses (Lingard et al., 1999).

Poster presentations may be as oral or poster presentations in scientific environments. In oral presentations, didactic presentation of detailed knowledge is performed (Rowe et al., 2009). In another type of poster presentation, authors may attend their posters for a short time for presentation or not (Berg, 2005).

In classical poster presentation, presenting person aims to convey scientific results of his/her study in a short, concise, striking and clear way (Rowe et al., 2009).
Poster size, text, graphics, tables and figures, color scheme and content may affect attention drawn to posters. In the literature, some of guidelines for a good poster preparation have been defined (Ballisteri, 2002; Haber et al., 2001; Bordage, 1994; Donnelly, 1997).

We aimed here to present our experiences in poster presentations as well as our opinions about place of poster presentations in academic knowledge transfer in oncology field, and how posters should be prepared.

\section{Materials and Methods}

The study was performed between November 2013 and January 2014 by oncologists who are works in Medical and Radiation Oncology departments. Survey forms were distributed via e-mail or during conferences to oncologists or to themselves at oncology centers that they worked by couriers. Local ethics committee approvals and informed consents of all participants were provided before starting up the study.

Survey form consisted of fourty questions. Twentytwo questions in Table 1 were for evaluation of participant characteristics and their experiences in poster presentation. Eighteen questions in Table 2 were aimed to

${ }^{1}$ Department of Medical Oncology, ${ }^{2}$ Department of Radiation Oncology, Regional Teaching and Research Hospital, Erzurum, ${ }^{3}$ Department of Medical Oncology, Istanbul University, Istanbul, ${ }^{4}$ Department of Medical Oncology, Akdeniz University, Antalya, Turkey*For correspondence: tımurkoca3@gmail.com 
Table 1. Questions Evaluating Participant Characteristics and their Experiences in Poster Presentation

\begin{tabular}{|c|c|c|c|}
\hline \multirow[t]{2}{*}{ Characteristic } & & \multicolumn{2}{|c|}{$\begin{array}{c}\text { No. of patients }(\%) \\
\text { or Mean } \pm \mathrm{SD}^{*}\end{array}$} \\
\hline & & \multicolumn{2}{|c|}{ Median (\%) } \\
\hline \multirow[t]{2}{*}{ Gender } & Male & 56 & $(56 \%)$ \\
\hline & Female & 44 & $(44 \%)$ \\
\hline \multirow[t]{5}{*}{ Age, year } & $<30$ & 6 & $(6 \%)$ \\
\hline & $30-35$ & 28 & $(28 \%)$ \\
\hline & $36-40$ & 31 & $(31 \%)$ \\
\hline & $41-50$ & 31 & $(31 \%)$ \\
\hline & $>50$ & 4 & $(4 \%)$ \\
\hline \multirow{2}{*}{ Occupation } & Medical oncologist & 43 & $(43 \%)$ \\
\hline & Radiation oncologist & 57 & $(57 \%)$ \\
\hline \multicolumn{4}{|c|}{ How long have you been working in oncology field? } \\
\hline & $1-3$ & 32 & $(32 \%)$ \\
\hline & $6-10$ & 31 & $(31 \%)$ \\
\hline & $11-15$ & 18 & $(18 \%)$ \\
\hline & $16-20$ & 15 & $(15 \%)$ \\
\hline & $>20$ & 4 & $(4 \%)$ \\
\hline \multicolumn{4}{|c|}{ What is your current academic title? } \\
\hline & Specialist & 68 & $(68 \%)$ \\
\hline & Assistant Professor & 11 & $(11 \%)$ \\
\hline & Associate Professor & 9 & $(9 \%)$ \\
\hline & Prof. & 12 & $(12 \%)$ \\
\hline \multicolumn{4}{|c|}{ Are you currently working at an academic environment? } \\
\hline & No & 11 & $(11 \%)$ \\
\hline & Yes & 89 & $(89 \%)$ \\
\hline \multicolumn{4}{|c|}{ What is the average number of congresses that you attend in a year? } \\
\hline & 0 & 1 & $(1 \%)$ \\
\hline & $1-3$ & 75 & $(75 \%)$ \\
\hline & $4-5$ & 17 & $(17 \%)$ \\
\hline & $6-10$ & 7 & $(7 \%)$ \\
\hline & $>10$ & - & \\
\hline
\end{tabular}

What are the numbers of national and international congressesthat you have atended during 1 year?

$\begin{array}{llrr}\text { National } & 0 & 4 & (4 \%) \\ & 1-3 & 85 & (85 \%) \\ & 4-5 & 10 & (10 \%) \\ \text { International } & 6-10 & 1 & (1 \%) \\ & >10 & - & \\ & 1-3 & 40 & (40 \%) \\ & 4-5 & 58 & (58 \%) \\ & 6-10 & 1 & (1 \%) \\ & >10 & 1 & (1 \%)\end{array}$

If you have accepted posters, how many of them are accepted in national and international congresses during 1 year?

\begin{tabular}{|c|c|c|c|}
\hline \multirow[t]{5}{*}{ National } & 0 & 13 & $(13 \%)$ \\
\hline & $1-3$ & 45 & $(45 \%)$ \\
\hline & $4-5$ & 20 & $(20 \%)$ \\
\hline & $6-10$ & 7 & $(7 \%)$ \\
\hline & $>10$ & 15 & $(15 \%)$ \\
\hline \multirow[t]{5}{*}{ International } & 0 & 39 & $(39 \%)$ \\
\hline & $1-3$ & 44 & $(44 \%)$ \\
\hline & $4-5$ & 11 & $(11 \%)$ \\
\hline & $6-10$ & 3 & $(3 \%)$ \\
\hline & $>10$ & 3 & $(3 \%)$ \\
\hline \multicolumn{4}{|c|}{ Did you have any oral presentations in congresses? } \\
\hline & Yes & 53 & $(53 \%)$ \\
\hline & No & 47 & $(47 \%)$ \\
\hline \multicolumn{4}{|c|}{$\begin{array}{l}\text { Which selection criteria do you think is "the most" important one in definin } \\
\text { poster as an oral presentation? }\end{array}$} \\
\hline & Scientific value & 62 & $(62 \%)$ \\
\hline & $\begin{array}{l}\text { Personal relationship } \\
\text { with the committee members }\end{array}$ & 18 & $(18 \%)$ \\
\hline & The name of the healthcare center & 17 & $(17 \%)$ \\
\hline & The name of the poster owner & 1 & $(1 \%)$ \\
\hline & None & 2 & $(2 \%)$ \\
\hline \multicolumn{4}{|c|}{ Have you ever participate in poster discussions? } \\
\hline & Yes & 74 & $(74 \%)$ \\
\hline & No & 26 & $(26 \%)$ \\
\hline
\end{tabular}

evaluate general view-points of participants about poster presentation and how poster presentation format should be in oncology field.

Study results were evaluated by answers to open ended and 5-point Likert scale (1=strongly disagree, $2=$ disagree, $3=$ neither agree/disagree, $4=$ agree, $5=$ strongly disagree) questions.

\begin{tabular}{lrc}
\hline Characteristic & $\begin{array}{r}\text { No. of patients (\%) } \\
\text { or Mean } \pm \text { SD* } \\
\text { Median }\end{array}$ \\
& $(\%)$ \\
\hline Do you think that posters you have sent to congresses have scientific values? \\
No, I do not agree (Definitely No) & 1 & $(1 \%)$ \\
No, I do not agree (No) & 5 & $(5 \%)$ \\
I cannot say Yes or No (I am unsure) & 28 & $(28 \%)$ \\
I agree (Yes) & 57 & $(57 \%)$ \\
I always agree (Definitely Yes) & 9 & $(9 \%)$ \\
What is "the most important" reason for you to send posters to congresses? & 31 & $(31 \%)$ \\
To present study results in a short-time interval & 27 & $(27 \%)$ \\
To define points for manucript writing process after criticisms & 17 & $(17 \%)$ \\
For an academic title & 9 & $(9 \%)$ \\
To provide congress registration or financial support & 16 & $(16 \%)$ \\
None & &
\end{tabular}

Would you prepare a poster if you are not interested in the academic title or congress registration or financial support?

$\begin{array}{lrr}\text { No, I do not agree (Definitely No) } & 11 & (11 \%) \\ \text { No, I do not agree (No) } & 13 & (13 \%) \\ \text { I cannot say Yes or No (I am unsure) } & 22 & (22 \%) \\ \text { I agree (Yes) } & 41 & (41 \%) \\ \text { I always agree (Definitely Yes) } & 13 & (13 \%) \\ \text { Do you visit poster stands in congresses that you attend? } & & \\ \text { Never } & 1 & (1 \%) \\ \text { Very rarely } & 6 & (6 \%) \\ \text { Sometimes } & 34 & (34 \%) \\ \text { Commonly } & 47 & (47 \%) \\ \text { Always } & 12 & (12 \%)\end{array}$

Always $12 \quad(12 \%)$

What is "the most important" reason for you to visit poster stands in congresses that you attend?

To review posters of my friends or mine (except the first name) $11 \quad(11 \%)$

$\begin{array}{lll}\text { I visit if I have a poster (as the first name) } & 7 & (7 \%)\end{array}$

$\begin{array}{lll}\text { To provide ideas for my future studies } & 33 \quad(33 \%)\end{array}$

To review studies conducted in my field of interest $\quad 47 \quad(47 \%)$

None $2 \quad(2 \%)$

Do you think that posters you have sent to congresses contain all details that congress attendees require?

No, I do not agree (Definitely No) 1 (1\%)

$\begin{array}{lr}\text { No, I do not agree (No) } & 19(19 \%)\end{array}$

I cannot say Yes or No (I am unsure) $\quad 38 \quad(38 \%)$

$\begin{array}{lll}\text { I agree (Yes) } & 39 \quad(39 \%)\end{array}$

I always agree (Definitely Yes) $3 \quad 3 \%)$

Do you think posters you have sent to congresses have drawn many of congress attendees?

No, I do not agree (Definitely No) $11 \%$

No, I do not agree (No) $\quad 23 \quad(23 \%)$

I cannot say Yes or No (I am unsure) $\quad 47 \quad(47 \%)$

$\begin{array}{lll}\text { I agree (Yes) } & 29 \quad(29 \%)\end{array}$

I always agree (Definitely Yes)

Do you think poster presentations you have sent to congresses were an effective way for transfer of the knowledge?'

No, I do not agree (Definitely No) $2 \quad(2 \%)$

No, I do not agree (No) $\quad 22 \quad(22 \%)$

$\begin{array}{lll}\text { I cannot say Yes or No (I am unsure) } & 22 & (22 \%)\end{array}$

$\begin{array}{lll}\text { I agree (Yes) } & 53 \quad(53 \%)\end{array}$

I always agree (Definitely Yes)

Do you think that posters you have sent to congresses were beautiful presentations of your studies?

No, I do not agree (Definitely No) $1 \quad 1 \%$

No, I do not agree (No) $11 \quad(11 \%)$

$\begin{array}{lll}\text { I cannot say Yes or No (I am unsure) } & 21 \quad(21 \%)\end{array}$

$\begin{array}{lll}\text { I agree (Yes) } & 64 \quad(64 \%)\end{array}$

I always agree (Definitely Yes) $3 \quad(3 \%)$

How many posters sent to congress has been converted to scientific articles and accepted for international journal publication?

\begin{tabular}{lrr} 
All of them & 4 & $(4 \%)$ \\
Two of third & 17 & $(17 \%)$ \\
Half of them & 19 & $(19 \%)$ \\
Less then one third & 38 & $(38 \%)$ \\
None of them & 22 & $(22 \%)$ \\
\hline
\end{tabular}

\section{Statistical analysis}

Descriptive statistics were used to determine each statement (mean, standard deviation, and percentages). Open-ended questions were statistically analyzed with modified thematic analyses for the responses (Rice et al., 1999). 
Table 2. General Viewpoint of Participants in Poster Presentations in Oncology Field, and Questions Evaluating How a Poster Format should be. Responses to Survey (Attitudes and Opinions)

\begin{tabular}{|c|c|c|c|c|c|c|}
\hline Questions & $\begin{array}{l}\text { Mean } \\
(\mathrm{SD})\end{array}$ & $\begin{array}{c}\text { No. strongly disagree } \\
(\%)\end{array}$ & $\begin{array}{l}\text { No. disagree } \\
(\%)\end{array}$ & $\begin{array}{c}\text { No. neither agree or disagree } \\
(\%)\end{array}$ & $\begin{array}{l}\text { Yes agree } \\
\quad(\%)\end{array}$ & $\begin{array}{c}\text { Yes strongly agree } \\
(\%)\end{array}$ \\
\hline \multicolumn{7}{|c|}{ Do you think posters have "scientific values"? } \\
\hline & $2.63(0.73)$ & - & $8(8)$ & $28(28)$ & $57(57)$ & $7(7)$ \\
\hline \multicolumn{7}{|c|}{ Is poster presentation a good way to transfer oncological knowledge? } \\
\hline & $2.42(0.84)$ & $2(2)$ & $15(15)$ & $24(24)$ & $57(57)$ & $2(2)$ \\
\hline \multicolumn{7}{|c|}{ Should posters be accepted as academic publications in oncology field? } \\
\hline & $2.46(0.88)$ & $2(2)$ & $15(15)$ & $23(23)$ & $55(55)$ & $5(5)$ \\
\hline \multicolumn{7}{|c|}{ Do you think posters prepared in our country have scientific values? } \\
\hline & $2.18(0.86)$ & $4(4)$ & $15(15)$ & $42(42)$ & $37(37)$ & $2(2)$ \\
\hline \multicolumn{7}{|c|}{ Do you think that orally presented poters have more scientific values? } \\
\hline & $2.45(0.81)$ & $1(1)$ & $15(15)$ & $24(24)$ & $58(58)$ & $2(2)$ \\
\hline \multicolumn{7}{|c|}{ Is poster presentation an effective way to transfer subject related knowledge? } \\
\hline & $2.13(0.77)$ & - & $24(24)$ & $39(39)$ & $37(37)$ & - \\
\hline \multicolumn{7}{|c|}{ Do posters provide an opportunity for authors to present a debatable subject? } \\
\hline & $2.32(0.91)$ & $1(1)$ & $24(24)$ & $20(20)$ & $52(52)$ & $3(3)$ \\
\hline \multicolumn{7}{|c|}{ Do you think congress attendees discuss poster contents among themselves in and out of poster stand areas? } \\
\hline & $1.92(0.95)$ & $6(6)$ & $29(29)$ & $34(34)$ & $29(29)$ & $2(2)$ \\
\hline \multicolumn{7}{|c|}{ Do you think posters provide scientific benefits to attendees after the congress? } \\
\hline & $2.39(0.74)$ & - & $14(14)$ & $34(34)$ & $51(51)$ & $1(1)$ \\
\hline \multicolumn{7}{|c|}{ Is the "name of healthcare center" important for you while reviewing a poster? } \\
\hline & $2.41(1.00)$ & $6(6)$ & $13(13)$ & $21(21)$ & $54(54)$ & $6(6)$ \\
\hline \multicolumn{7}{|c|}{ Do you think it is important that a presenting person accompanies a poster? } \\
\hline & $2.47(1.02)$ & $5(5)$ & $15(15)$ & $17(17)$ & $54(54)$ & $9(9)$ \\
\hline \multicolumn{7}{|c|}{ While reviewing a poster, is halo effectc of presenting person (if female, her beauty; if male, his handsomeness with tidy dressings)? } \\
\hline & $1.69(1.17)$ & $18(18)$ & $31(31)$ & $18(18)$ & $30(30)$ & $3(3)$ \\
\hline \multicolumn{7}{|c|}{ Do you think poster size is important to reflect poster content? } \\
\hline & $2.45(0.95)$ & $3(3)$ & $17(17)$ & $18(18)$ & $56(56)$ & $6(6)$ \\
\hline \multicolumn{7}{|c|}{ Do you think appearance (graphics, tables, color scheme etc.) rather than text is important in posters? } \\
\hline & $2.64(0.88)$ & $1(1)$ & $14(14)$ & $15(15)$ & $60(60)$ & $10(10)$ \\
\hline \multicolumn{7}{|c|}{ Do you think simple/clear graphics/tables in posters may increase interest in poster content? } \\
\hline & $3.02(0.59)$ & - & $2(2)$ & $10(10)$ & $72(72)$ & $16(16)$ \\
\hline \multicolumn{7}{|c|}{ Do you think posters reflect not only scientific but also artistic talent of authors? } \\
\hline & $2.53(0.88)$ & $2(2)$ & $14(14)$ & $19(19)$ & $59(59)$ & $6(6)$ \\
\hline \multicolumn{7}{|c|}{ Do you think posters which are not aimed to be published as manuscripts should be presented in congresses? } \\
\hline & $2.44(0.83)$ & $2(2)$ & $11(11)$ & $33(33)$ & $49(49)$ & $5(5)$ \\
\hline \multicolumn{7}{|c|}{ Do you think such a survey study is important to investigate scientific value of poster presentation? } \\
\hline & $2.66(0.87)$ & $3(3)$ & $5(5)$ & $27(27)$ & $53(53)$ & $12(12)$ \\
\hline
\end{tabular}

\section{Results}

Out of 131 medical and radiation oncologists, 100 $(76 \%)$ of them answered the questions in the survey.

Questions for evaluation of participant characteristics and their experiences in poster presentation

Twenty-two questions in Table 1 were for evaluation of participant characteristics and their experiences in poster presentation. Of participants, $56 \%$ were males and $44 \%$ were females. Number of participants over 35 years of age was $66(66 \%)$, and they constituted the majority. Medical oncologists constituted $43 \%$ and radiation oncologists constituted $57 \%$ of the participants. Majority of oncologists have been working in this field for 15 years or more $(81 \%)$. Number of oncologists with an academic title was $32(32 \%)$, whereas without any academic title was $68(68 \%)$. Majority of participants were working in an academic environment (89\%), and number of the ones who attended $\leq 5$ congresses in a year was 93 (93\%). Of participants, who attended $\leq 3$ congresses in a year, $89 \%$ were attending international and $98 \%$ were attending national congresses. Among participants, the ones with 1 to 3 posters acceptance in a year constituted the majority; $45 \%$ of them were nationally and $44 \%$ were internationally accepted. Number of participants who performed oral presentations in congresses was $53(53 \%)$.

Participants believed that the most common selection criteria for an oral presentation was "the scientific value" $(62 \%)$. The rate of oncologists attending poster discussions in congresses was $74 \%$. Of participants, $66 \%$ agreed or strongly agreed that posters had "poster that they sent to congresses had the scientific value". Thirty-one percent of participants declared that "the most important cause" that they sent posters to congresses were "to present their study results in a short time". The question "Would you prepare a poster if you are not required to have an academic title or to have a materialistic gain or to attend a congress?" was answered as "I agree" or "I strongly agree" by 54\% of participants. The question asking whether participants visited poster stands in congresses was answered as "sometimes" by $34 \%$, "mostly" by $47 \%$, and "always" by $12 \%$ of participants. Forty-seven percent of participants answered the question asking "the most important reason of their visiting poster stands in congresses" as "to see new studies in their most interested subjects".

Five out of first 22 questions in the survey were evaluating participants' posters, which were sent to congresses. The question asking whether participants thought that their posters contained all details required by congress attendees was answered as "neither agree nor disagree" by $38 \%$ and "I agree" or "I strongly agree" by 
$42 \%$ of study participants. The question asking whether posters of participants in congresses drew attention of many congress attendees was answered as "neither agree nor disagree" by $47 \%$ and as "I agree" in $29 \%$ of the participants. While answering the question whether poster presentation was an effective way of knowledge transfer, $54 \%$ study participants agreed or strongly agreed with it. Sixty-seven percent of study participants agreed or strongly agreed that their congress posters were beautiful presentations of their studies. When participants asked about what rate of their congress posters were published as articles in international journals, $38 \%$ of them said "less than one third" and $22 \%$ said "none of them".

General view-points of participants about poster presentations in oncology field and questions evaluating how a poster presentation format should be

Eighteen questions evaluating general view-points of participants about poster presentations in oncology field and how poster presentation format should be are given in Table 2. Five point Likert scale questions constituted all of the questions. Sixty-four percent of participants agreed or strongly agreed with the question asking whether posters presented in oncology field had scientific values. Fifty-nine percent of participants accepted that poster presentation was a good way for oncological knowledge transfer at. Moreover, $60 \%$ of participants agreed or strongly agreed that poster presentations should be accepted as academic publications for oncology field. When participants were asked whether oncology posters in Turkey had scientific values, $42 \%$ of them told that they were not sure of it and $39 \%$ agreed or strongly agreed that they were. When they were asked whether they believed oral presentations had much scientific value, $60 \%$ of participants told that they did. The other question asking whether poster presentation was an effective way to transfer adequate knowledge in oncology, 39\% said that they were not sure, whereas $37 \%$ agreed that they were. Fifty-five percent of participants agreed or strongly agreed that posters could provide an author to present a debatable subject. When participants were asked about their opinions whether congress attendees were discussing poster contents at and out of the poster area among themselves, $29 \%$ told that they did not think so; $34 \%$ told that they were not sure; and $31 \%$ told that they strongly believed so. The question asking whether posters provided significant scientific contribution to congress attendees after the congress was answered as "unsure about it" by $34 \%$, and as "I (strongly) agree" by $52 \%$ of study participants. Sixty percent of participants agreed or strongly agreed that sending oncology center was important to examine an oncology poster. Sixty-three percent of participants agreed or strongly agreed that it was important for examination of the poster if it was attended by a person. For the question to evaluate the halo effect (if female, her beauty; if male, his handsomeness with tidy dressings), $31 \%$ of participants disagreed that presenting person's appearance would be important to examine a poster; $18 \%$ claimed that they were unsure about it, whereas $33 \%$ agreed (or strongly agreed) that it would be.

In the survey, three questions, which were examining general view-points on poster presentations and how poster formats should be, were inquiring about appearances of posters. Sixty-two percent of participants agreed (strongly agreed) that poster sizes were important in reflecting poster contents. When they were asked whether appearance (graphic, table, color scheme etc.) was more important than the text in posters, $70 \%$ agreed (strongly agreed) that appearance was more important. Eighty-eight percent of participants agreed (or strongly agreed) that simple/ clear graphics and tables used in posters would increase attention to the poster content.

When participants asked whether posters reflected not only author's scientific personality but also artistic skill of him/her, 65\% agreed (strongly agreed) with it. When participants asked whether posters which would not be published later should be presented as posters in congresses, $33 \%$ of them said that they were unsure about it, whereas $54 \%$ agreed (or strongly agreed) with it.

In the survey, there was a question asking opinions of participants whether performing such a survey study was significant for evaluation of scientific value of oncological posters (the last question in Table 2). Sixty-five percent of participants agreed (or strongly agreed) with the significance of the study.

\section{Discussion}

Our present study is the first study, in which medical and radiation oncologists evaluated academic poster presentations in the field of oncology. Majority of published literatures related to poster presentation embraced poster preparation methods, and benefits and limitations of posters in knowledge transfer as an academic tool.

In our study, we defined that poster presentation was a good way for oncological knowledge transfer for oncologists and it should be accepted as a way of academic publication. Moreover, we defined that simple/ clearly prepared poster graphics and tables might increase audience attention for poster contents. We determined that poster appearance (graphic, table, color scheme etc.) was more important than the text itself. Additionally, we realized that presence of an accompanying person with the poster was important for the presenter. It was determined that halo effect was important for approximately one third of participants during poster reviews.

Posters have significant advantages when compared with oral presentations. The significant advantages are that they can be available for a longer time; and they can provide close and detailed interactions between interested audience and authors. However, posters are generally incomplete in explaining authors' ideas, and audiences cannot learn about other audiences' questions and answers. Actually posters are equivalent to oral presentations, but many young participants prefer oral presentations. However, original studies are often presented preferably as posters, and the rate of original studies is quite low among oral presentations (De maria, 2010). Also, participants in our study preferred oral presentations thinking that their scientific contributions were higher.

It should be discussed how much Digital Interactive Poster Presentation (DIPP) and media posters, which 
have been especially in use since year 2001, are useful in knowledge transfer (De Simeone et al., 2001; Rowe et al., 2009).

Goodhand et al reported that congress attendees visited poster presentations very rarely and the ones who visited could hardly remember about poster contents. They also mentioned that attraction of posters should be increased by high quality data containing pictures or graphics rather than large number of words (Goodhand et al., 2011). Our study participants told that they visited poster stands at high rates in congresses, and they believed that appearances (graphic, table, color scheme etc.) were more significant than texts in posters.

It might be claimed that impressions gained from researches which investigated poster presentations in congresses of different medical fields were different (Sarwal K et al., 2013; Sutcliffe SB, 2012; Cannon G et al., 2012; Bryant $\mathrm{H}$ et al., 2012). According to information from limited number of reviews, interest in poster presentations, and significance of poster presentation in knowledge transfer were variable in different medical fields (De maria, 2010; Goodhand et al., 2011; Dumville et al., 2008; Dogan et al., 2013). In our study, majority of our participants believed that poster presentations were an important method for knowledge transfer in oncology field.

The present study was performed on experienced participants, who worked in oncology field for long durations. However, number of annual congresses that participants can attend is lower than their colleagues in developed countries. This condition can be explained in developing countries by financial shortness and inadequate sponsorship. Besides, it has been observed that oncologists who could attend congresses were mainly preferring international congresses (Rowe et al., 2009).

In conclusion, although posters are accepted as an important method of knowledge transfer, variations in their designs cause different access rates for scientific groups. This variation is evaluated in oncology field in our study. Participants believe that poster presentation is an important method to convey data transfer in oncology field.

\section{References}

Berg J (2005). Creating a professional poster presentation: focus on nurse practitioners. J American AcadNurse Practitioners, 17, 245-8.

Balistreri WF (2002). Giving an effective presentation. J Ped Gastroenteral Nutr, 35, 1-4.

Bordage G (1994). Elaborated knowledge: a key to successful diagnostic thinking. Acad Med, 69, 883-5.

Bryant H, Shin RH, Forman D, et al (2012). Managing population health to prevent and detect cancer and non-communicable diseases. Asian Pacific J Cancer Prev, 13, 13-22.

Cannon G, Gupta P, Gomes F, et al (2012). Prevention of cancer and non-communicable diseases. Asian Pacific J Cancer Prev, 13, 3-11.

De Maria AN (2010). Whither the Oral Abstract Presentation. $J A C C, \mathbf{5 5}, 1752-3$.

De Simone R, Rodrian J, Osswald B, et al (2001). Initial experience with a new communication tool: the 'Digital
Interactive Poster Presentation'. Eur J Cardio-thoracic Surgery, 19, 953-5.

Dogan E, Durmusoglu M, Erdag TK (2013). Publication rates of presentations which were presented at Turkish National Rhinology Congresses. Kulak Burun Bogaz Ihtis Derg, 23, 283-7.

Donnelly W J(1997). The language of medical case histories. Ann Intern Med, 127, 1045-8.

Dumville JC, Petherick ES, Cullum N (2008). When will I see you again? The fate of research findings from international wound care conferences. Int Wound J, 5, 26-33.

Goodhand JR, Giles CL, Wahed M (2011). Poster presentations at medical conferences: an effective way of disseminating research? Clin Med, 11, 138-41.

Haber RJ, Lingard LA (2001). Learning oral presentation skill: a rhetorical analysis with pedagogical and professional implications. J Gen Intern Med, 16, 308-14.

Lingard L, Haber RJ (1999). Teaching and learning communication in medicine; A rhetorical approach. Acad Med, 74, 507-10.

Rice P, Ezzy D (1999). Qualitative Research Methods South Melbourne: Oxford University Press.

Rowe N, Il D (2009). What impact do posters have on academic knowledge transfer? A pilot survey on author attitudes and experiences. BMC Medical Education, 9, 71.

Rowe N, Ilic D (2009). Innovating professional knowledge transfer: from academic poster to 'MediaPoster'. Medical Education, 43, 496.

Sarwal K, Trapido EJ, Sutcliffe S, et al (2013). Impact and evaluation of international cancer control congresses. Asian Pacific J Cancer Prev, 14, 1159-63

Smith P, Fuller G, Dunstan F (2004). Scoring posters at scientific meetings: first impressions count. J Royal Soc Med, 97, 340-1.

Sutcliffe SB (2012). The $4^{\text {th }}$ International Cancer Control Congress. Asian Pacific J Cancer Prev, 13, 1-2. 